\title{
Influence of packaging attributes on consumer
}

\author{
evaluation of fresh cod
}

\author{
Morten Heide ${ }^{\mathrm{a} *}$ and Svein Ottar Olsen ${ }^{\mathrm{b}}$
}

aNofima AS, P.O. Box 6122, 9291 Troms $\varnothing$, Norway, e-mail: morten.heide@nofima.no

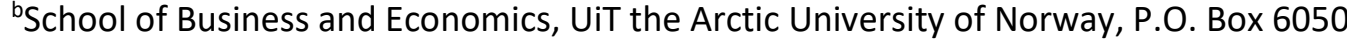 \\ Langnes, 9037 Troms $\varnothing$, Norway, e-mail: svein.o.olsen@uit.no
}

\begin{abstract}
Packaging attributes have an important role in attracting consumer attention, creating expectations and influencing food choice. In this study, conjoint and cluster analysis were used to investigate the importance of visual attributes (packaging shape and colour) and informational attributes (freshness indicators, shelf life and freshness statements, convenience and taste information) for fresh cod. The consumer segments were profiled using individual consumer characteristics. A conjoint analysis of a nationwide representative sample of 503 Norwegian consumers revealed that the informational attributes were more important than the visual attributes. The most important factors for consumers when choosing cod fillets were two freshness attributes (with a total relative importance value of 45\%). Cognitive freshness information was found to be more important than affective information. A cluster analysis of the part-worth utility scores revealed three clusters: packaging, quality and convenience. The packaging segment was the largest (with approximately $50 \%$ of the consumers) and the consumers in this segment preferred the visual attributes of shape and colour. The results of an ANOVA performed on the measurements of the individual characteristics revealed significant differences among the segment profiles. The findings of this study can be used by the seafood industry to design packaging for cod products that better match consumers' needs and expectations.
\end{abstract}

\section{Keywords:}

Conjoint; packaging attributes; cluster analysis; cod 


\section{Introduction}

Previous research has shown that packaging plays an important role in attracting consumer attention, formulating consumers' evaluation of quality and value and influencing their food choice (Karimi, Mahdieh, \& Rahmani, 2013; Silayoi \& Speece, 2007). These studies also tested the packaging effects of various fresh products, such as fresh produce/sweet cherries (Koutsimanis, Getter, Behe, Harte, \& Almenar, 2012), fresh apples (Endrizzi, Corollaro, Demattè, Aprea, Charles, Franco, \& Gasperi, 2015) and fresh meat (Grunert, 1997). However, a recent review of consumer purchasing behavior towards fish and seafood (Carlucci, Nocella, De Devitiis, Viscecchia, Bimbo, \& Nardone, 2015) shows that packaging attributes seems not to have received enough attention by researchers. Furthermore, no study has investigated the specific influence of food packaging attributes on consumers' evaluations of fresh cod.

Food products use a wide range of packaging attributes by combining colours, designs, shapes, functionalities, technical features, symbols and messages (Nancarrow, Wright, \& Brace, 1998). In a review of the main drivers that lead to packaging design, Azzi, Battini, Persona, \& Sgarbossa (2012) identified various attributes related to ergonomics, logistics, sustainability, safety and marketing. In the context of food packaging, Silayoi and Speece (2004) divided packaging attributes into two main categories: visual attributes and informational attributes. Visual attributes consist of graphics, colours, placements, photos, sizes and shapes of packaging, whereas informational attributes relate to information provided on and technologies used in the packaging. Information attributes on food packaging typically consist of labelling and brand information (Silayoi \& Speece, 2004), such as the product's technical characteristics, ingredients and serving size, as well as information related to recommended uses, cooking instructions, instructions for proper disposal and shelf life (Harcar \& Karakaya, 2005).

Following Silayoi and Speece (2007), this study examines shape and colour as the primary visual attributes while information regarding taste (Carlucci et al., 2015), convenience (Olsen, Scholderer, Brunso, \& Verbeke, 2007) and freshness (statements/shelf life) are used as the primary informational attributes. The first goal of this study is to evaluate the relative importance of the visual and informational packaging attributes of fresh cod through a conjoint study. The identification of these attributes might help the industry design a package that closely matches consumers' needs and expectations (Deliza \& MacFie, 1996) and contribute to higher product satisfaction and choice of fresh cod among Norwegian consumers.

When developing, testing and profiling the important packaging attributes of, for example, cod, it is important to note that not all consumers evaluate and value packaging in the same way 
(Golan, Kuchler, Mitchell, Greene, \& Jessup, 2001; Verbeke, 2008). To address this challenge, the second goal of this study is to segment the consumers based on preference for different packaging attributes using cluster analysis (Hair, Anderson, Tatham, \& William, 1998). These segments are validated (predicted) against the survey responses regarding the individual characteristics of consumers, specifically consumption and preferences, health and seafood involvement, knowledge about quality, willingness to pay and demographics. Although segmentation and cluster analysis has become increasingly popular in consumer sciences (DeSarbo and DeSarbo, 2013), the interaction between visual and informational attributes of fresh products has received limited attention. Thus, this study contributes to the existing literature by exploring how the combination of visual and informational attributes influence consumer preference for fresh products. .

\section{Theoretical framework}

In the following, this study discusses, defines and reviews how and why visual and informational attributes and personal characteristics may influence consumer evaluation of fresh cod.

\subsection{Visual attributes}

Several studies of food products have considered shape and colour to be important visual packaging attributes (Ares \& Deliza, 2010; Marshall, Stuart, \& Bell, 2006; Silayoi \& Speece, 2007). Packaging shape consist of different features such as size, relative height, shape angularity and rectangular ratios (Raghubir, \& Greenleaf, 2006; Zhang, Feick, \& Price, 2006). For example, several studies suggest that angular shapes tend to stimulate consumer's association with their traits and emotions that express energy, toughness, and strength, whereas rounded shapes tend to stimulate associations with friendless, harmony and approachability (Becker, van Rompay, Schifferstein, \& Galetzka, 2011; Zhang et al., 2006). However, shape need to be adapted to physical characteristics with the product, the demand from the retailing outlets and consumer's expectations and preferences (e.g., fresh versus frozen seafood). We are aware of one study, which have tested consumers evaluation of different packing formats of pre-packed fresh seafood. Mueller Loose, Peschel, and Grebitus (2013) found that packaging shape had small effect for oysters. The present study includes and tests the three most relevant packaging techniques for fresh seafood in the Norwegian context; modified atmosphere packaging (MAP), vacuum packaging and skin packaging. Skin packaging is the most innovative and novel packing method, and only used on meat products in the Norwegian market. Novel packaging grabs consumers' attention and increases the probability of an involuntary attention response (Labrecque, Patrick, \& Milne, 2013). Thus it may represent a new 
possibility for packaging that can help differentiate cod products from salmon and other fish products.

Past research shows that colour affects consumer attention, affect, emotion, and perception of products in different ways (Grimes \& Doole, 1998; Labrecque \& Milne, 2012). Colour is used on packaging in order to stimulate associations towards luxury, exclusivity, nature, hygiene, quality, security, trust etc. (Ampuero \& Vila, 2006; Labrecque \& Milne, 2012). Colour is suggested to influence evaluations of food such as fish (Alfnes, Guttormsen, Steine, \& Kolstad, 2006) and meat (Grebitus, Jensen, Roosen, \& Sebranek, 2013). However, research on the effect of different colours has lacked a clear consensus. Some researchers feel that human responses to colours are stable and applicable to everyone, whereas others assert that responses and preferences to colours vary across culture, gender and age, among others (Singh, 2006). Black is a colour that often provide associations toward high quality, luxury and premium products across products, individuals and culture (Gimes \& Doole, 1998; Labrecque \& Milne, 2012). White is associated with simplicity, cleanness, clear and hygiene, and gold and silver stimulate feelings and emotions toward power, wealth, prestige, luxury and high quality (Labrecque \& Milne, 2012). Blue is often used on packages of seafood because it gives associations toward water and ocean, but it also signalize intelligence, trust, communication and competence (Labrecque \& Milne, 2012). This study tests the effects of black in order to signal premium quality and silver as the most widely used color for packing of fresh seafood in Norway.

\subsection{Informational elements}

A number of informational elements can be included on seafood packaging. Based on previous research, the present study focused on taste, convenience and freshness (Carlucci et al., 2015; Olsen, 2004; Olsen et al., 2007).

\subsubsection{Information about taste}

As an attitudinal and informative construct, taste is categorized as a general sensory quality in the same ways as texture, flavour, smell, temperature, appearance, filling and preparation (Aikman, Crites, \& Fabrigar, 2006). Several studies has found taste is the most important attributes for consumer choice of food products (Cardello, \& Schutz, 2003; Tepper, \& Trail, 1998), included choice of seafood (Carlucci et al., 2015; Olsen, 2004). As an informational cue, taste is mostly promoted to increase expectations about premium quality ("good", "excellent", "tasty"), but also to signalize differential values such as sweet, bitterness, natural, etc. Since cod has a neutral or mild 
taste that makes it suitable for a wide range of culinary purposes (Otterå, Carlehög, Karlsen, Akse, Borthen, \& Eilertsen, 2007), the present study focused on the item 'natural mild taste'. The term 'natural' was included to emphasise that additives, spices or brine had not been used in the product. To some degree, this information has been used by the industry to profile fresh cod in Norway. However, there is no empirical evidence about the influence of this type of information on consumer evaluation.

\subsubsection{Product convenience}

Consumer attitudes towards the saving of time and effort in the planning, buying or use of products or services are considered the main elements in convenience orientation (Berry, Seiders, \& Grewal, 2002). ). Convenience is believed to be one of the most important determinants of food choice (Steptoe, Pollard, \& Wardle, 1995), including the choice of seafood in general (Carlucci et al., 2015) included Norway (Olsen et al., 2007). Meal convenience is also suggested to be related to different stages in the consumption process (Candel, 2001; Gofton, 1995): planning, acquisition/ purchasing, preparation, cooking, consumption/eating, and disposal. At each stage, convenience can play a role, and may differ in its importance between different situational contexts. In addition, studies have shown that many consumers feel insecure about preparation methods and perceive seafood preparation as a difficult and time-consuming task (Birch \& Lawley, 2012; Bruns $\varnothing$, Verbeke, Olsen, \& Jeppesen, 2009). Thus, "quick and easy", as used in this study, is frequently used as an item to assess perceived product convenience in consumer's food surveys (Candel, 2001; Olsen et al., 2007). Consumers expectations about how much time they want to consider as convenient differ over time and between consumers. Most advertisements in Norwegian media use 15 and 20 minutes as basis for a "fast dinner". This study uses 15 minutes as an indicator of a convenient meal. Finally "skin and boneless" was used to illustrate less time and energy for preparation. This is a statement often used by producers on both fresh and frozen fish fillets to emphasise convenience.

\subsubsection{Indicators of freshness}

Previous literature refer to freshness as a multidimensional construct because consumers evaluate freshness of fish based on both sensory attributes like smell, colour and appearance, and non-sensory attributes like branding and labelling (Carlucci et al., 2015; Zhang, Lusk, Mirosa, \& Oey 2016;). Freshness is of ultimate importance in consumers' evaluations of perceived quality and satisfaction with fish in general and fresh fish in particular (Carlucci et al., 2015; Olsen, 2004). Individuals that are more knowledgeable and experienced fish consumers are suggested to be more 
confident in their ability to judge the freshness of fish by using intrinsic cues such as smell and appearance, e.g. the colour of eyes and gills (Brunsø et al., 2009). Hence, less experienced consumers need extrinsic cues, such as outlets, branding and labelling (e.g. best before date, days since catch/harvest, geographical origin) to help reduce the perceived risk of making a wrong choice (Carlucci et al., 2015). Thus, this study tests if consumers evaluate seafood products differently if the information about freshness varied between four common informational cues Norwegian seafood suppliers use in their promotion of fresh pre-packed cod. Those informational cues are presented in the following.

Previous research has shown that the effect of information can be influenced by individual differences in need for affect or cognition (Haddock, Maio, Arnold, \& Huskinson, 2008). Affective information refers to feelings or emotions associated with an attitude object and has become more and more important for the differential advantage in food markets because most products are similar with respect to quality, convenience and price (Schifferstein, Fenko, Desmet, Labbe, \& Martin, 2013). Cognitive information refers to beliefs or thoughts associated with an attitude object (Aikman et al., 2006). Affect-based information is more effective among individuals in need of affect (Huskinson \& Haddock, 2004), whereas cognition-based information is more effective among consumers in need of cognition (Petty, Briñol, Loersch, \& McCaslin, 2009). Thus, this study includes a distinction between cognitive information ("Filleted and packed within 6 hours") and affective information ("Unique freshness") associated with pre-packed fresh cod. To our knowledge not study has investigates if consumers prefer affective or cognitive statements about freshness of fish.

Information about shelf life can be important for how consumer evaluate products (Harcar \& Karakaya, 2005). Shelf life indicates the recommended maximum time for which products can be stored (or used) under expected (or specified) conditions of distribution, storage and display. Ragaert, Verbeke, Devlieghere, \& Debevere (2004) found that shelf life was one of the most important product attributes when purchasing minimally processed vegetables and packaged fruit. Using factor analysis, their study also indicated that shelf life could be used as a proxy of credence attributes (healthiness, nutritional value and freshness) during consumers' purchasing decisionmaking processes. Since all fresh, pre-packed seafood products sold within the European Union (EU) are required to be labelled with a 'use-by' date (EU Directive 2000/13), all consumers purchasing fresh, pre-packed cod will be presented with shelf life information. Previous research show that shelf life information can have different impact on consumer acceptance depending on the product type. Gerbitus, Jensen, \& Roosen found no differences in preference for beef with 3, 5 and 14 days' shelf life among US and German consumers. For cod fillets $\varnothing$ stli, Esaiassen, Garitta, Nøstvold, \& Hough (2013) found that consumers accepted a shelf life of approximately 11 days when no capture date 
information was given. However, when capture date information was available, the accepted shelf life decreased to approximately 7 days. Wansink \& Wright (2006) showed a similar effect for yogurt. Thus, this study uses 8 and 12 days shelf life, simulating the shelf life of fresh fish when stored under different conditions (temperatures of $4^{\circ} \mathrm{C}$ and $0^{\circ} \mathrm{C}$ respectively).

\subsection{Individual characteristics}

Based on previous research, a number of individual characteristics that influence seafood consumption were chosen to profile the segments (Olsen et al., 2007; Pieniak, Verbeke, Olsen, Hansen, \& Bruns $\varnothing, 2010 ;$ Verbeke, 2008; Verbeke \& Vackier, 2005). The profiling variables relate to seven variables or constructs: 1) cod consumption and 2) preferences, 3 ) health involvement, 4) seafood involvement, 5) knowledge about quality, 6) willingness to pay and 7) demographics.

\subsubsection{Consumption and preference for cod}

Consumption frequency was included in this study since it is a direct measurement of behaviour and included in previous studies regarding seafood consumption (for a recent review, see Carlucci et al., 2015). Consumption frequency has also been used in a number of studies to profile different fish consumer segments (Bruns $\varnothing$ et al., 2009; Verbeke, Vermeir, \& Bruns $\varnothing$, 2007)

Since sensory characteristics are product specific, most studies use attitudes toward eating fish, satisfaction or general preferences as proxies for sensory perception of seafood (Carlussi et al. 2012). Preferences, as general like or dislike, have been suggested as one of the most important factors that influence the consumption of and loyalty toward seafood (Carllussi et al., 2015), including seafood among Norwegian consumers (Olsen, 2004).

\subsubsection{Involvement in health and fish}

Involvement refers to the personal relevance and importance attached to an object based on inherent needs, values and interests (Zaichkowsky, 1985). Involvement in food (Marshall \& Bell, 2004), fish (Olsen, 2001), or healthy eating are often related to food or fish consumption (Verbeke \& Vackier, 2005). Sapp and Jensen (1998) tested the health belief model for its ability to predict actual dietary quality and behaviour. Of the 15 independent variables, product and health involvement (consciousness) were the most important determinants. In the case of fish, involvement in both 
health and fish influences frequency of product usage (Carlucci et al., 2015; Juhl \& Poulsen, 2000; Olsen, 2003).

\subsubsection{Knowledge about quality}

Many consumers find it difficult to evaluate food quality, especially for unbranded and highly perishable food products such as fresh fish (Juhl \& Poulsen, 2000). Cognitive capacity, experiences, interests in information and objective and subjective knowledge differ among consumers (Verbeke et al., 2007). Thus, individual differences in consumers' knowledge or capacity to evaluate food quality have numerous consequences, e.g. in terms of behaviour, beliefs, attitudes and consumers' search for and use of information sources during decision-making. The reason for this is that expected quality influences a wide range of attitudes and behaviours from meal preparation methods to future purchasing decisions (Bruns $\varnothing$, Fjord, \& Grunert, 2002). Previous studies has shown that subjective knowledge is found to be more strongly associated with behaviour than actual (objective) knowledge (Pieniak, Verbeke, \& Scholderer, 2010; Verbeke et al., 2007). Thus, this study include subjective knowledge about fish quality as a profiling variable.

\subsubsection{Willingness to pay}

Fresh cod is among the most expensive commonly used fish products in Norway. The introduction of pre-packed fresh cod has not only made cod more available but also helped introduce cheaper products with fixed low prices. Economists, psychologists and marketing researchers use different research techniques to measure willingness to pay (WTP) (Wertenbroch \& Skiera, 2002). For example, WTP can be measured either from actual market transactions or from survey data (stated preferences). Transaction data have high external validity, but such data may be difficult to obtain, especially for new products or concepts (Breidert, Hahsler, \& Reutterer, 2006; Knetsch \& Sinden, 1984). Thus, since the combination of packaging attributes does not exist in the marketplace (and testing all the combinations are too expensive and time consuming), the present study utilised survey data.

Survey-based techniques for measuring WTP can be divided into two types, direct and indirect surveys. In direct surveys, respondents are asked to state how much they would be willing to pay for a product. In indirect surveys, some sort of rating or ranking procedure for different products is used, in order to estimate a preference structure from which WTP can be derived. Conjoint analysis is an example of indirect surveying methods (Breidert et al., 2006). The main issue when choosing 
between direct or indirect methods is whether one of the methods has a higher validity than the other. Previous empirical studies generally failed to find any systematic differences between results when using conjoint analysis and direct surveys to measure WTP (Miller, Hofstetter, Krohmer, \& Zhang, 2011; Sattler \& Hensel-Börner, 2003). Based on this research, we chose to use a direct survey approach to measure WTP as a profiling variable, and focus on other attributes in the conjoint analysis.

\section{Materials and methods}

\subsection{Data collection}

In the present study, an online survey was used. Participants were selected based on the following criteria: those who stated that they had eaten fish during the last year and those who were involved in household purchasing decisions in general and fish purchasing in particular. A nationwide representative sample of 503 Norwegian consumers ( $54 \%$ female, $46 \%$ male) was used, with an average respondent age of 45.5 years. The data was collected by YouGov, which is a recognised market research company with offices worldwide. YouGov currently includes a database of approximately 30,000 Norwegian consumers. The study was conducted in December 2015, a period of the year when fresh cod fillets are usually not heavily promoted in the Norwegian market.

A two-part consumer survey was used to gain insight into the influence of packaging attributes on consumers' decision-making processes for fresh cod. In the first part, the importance of specific packaging elements to consumers was evaluated in a conjoint study. To evaluate the visual attributes, the consumers were presented with pictures of actual products with the different colours (black and silver) and packaging technologies (MAP, vacuum and skin packaging). Under the pictures, the different informational elements were presented. In the second part, the consumers answered survey questions regarding their individual characteristics presented above.

\subsection{Survey instrument development}

In the present study, fish consumption behaviour was a self-reported item that was measured as total fresh cod fillet consumption frequency, based on a nine-point scale ranging from 'never' (1) to 'three or more times a week' (9). The scale was recalculated to cod fillet consumption per year.

Preference for fresh cod was measured on a seven-point scale ranging from 'dislikes' (1) to 'likes' (7). 
"Importance" and "means a lot" are, both in psychology and consumer behaviour, the mostused terms for assessing involvement (Boninger, Krosnick, \& Berent, 1995; Zaichkowsky, 1985). Health involvement was measured using two items from Pieniak et al. (2008), i.e. 'Health is very important to me' and 'Health means a lot to me', and one item from Olsen (2003), i.e. 'I do what I can to stay healthy'. All of the items were scored on a seven-point Likert-scale ranging from 'totally disagree' (1) to 'totally agree' (7). In addition, fish involvement was measured by the following three items based on a seven-point Likert scale ranging from 'totally disagree' to 'totally agree': 'Fish is an important part of my diet'; 'It means a lot to me to have fish for dinner'; and 'I am very concerned about eating fish for dinner' (Olsen, 2001; Olsen \& Ruiz, 2008).

Following Pieniak (2007), the present study measured subjective knowledge about quality with three items based on a seven-point Likert scale ranging from 'totally disagree' to 'totally agree': 'Compared to the average person, I know a lot about how to evaluate the quality of fish'; 'People who I know consider me to be an expert in fish quality'; and 'I have a lot of knowledge about how to evaluate good- and bad-quality fish'.

In consumer surveys, willingness to pay (WTP) is often framed toward important or salient attributes justifying consumers' needs or value for products and/or services (Zeithaml, 1988). WTP in the present study was framed toward three different freshness levels of the cod fillets: 12 hours, 2 days and 4 days. As previously explained, freshness is an important purchasing criterion for fish; thus, testing willingness to pay for different freshness levels is important. Consumers received the following information before stating their expectations for what the fish would cost at a local supermarket: 'Usually, this product is sold in supermarkets approximately five days after catch. The price varies, but it is, on average, approximately 150 Norwegian kroner per kilo. How much are you willing to pay for a packaged cod fillet that is "very fresh"'.

\subsection{Conjoint analysis design}

Conjoint analysis is a research technique used to evaluate factors that influence consumers' product preferences, trade-offs and, therefore, purchasing decisions (Green, Krieger, \& Wind, 2001). More specifically, conjoint analysis studies the affinity of consumers towards specific configurations of product attributes. When considering the attributes and levels, these should be carefully chosen to best represent what would be realistic in the market (Gil \& Sanchez, 1997). The relative importance of each attribute can be identified and compared to other attributes of one or more products. The results of the conjoint analysis can help identify the market segments between consumers with similar affinities towards one or more product attributes (Hair et al., 1998). In this study, individual consumer characteristics were used to profile different consumer segments, and the 
packaging attributes used in the conjoint analysis were divided into two categories: visual and informational attributes.

Conjoint analysis was applied in the first step of the data analysis to determine how individual consumers evaluate the different attribute levels of the packaging of fresh cod. This approach allowed the estimation of individual attribute levels on the overall utility of fresh cod, especially for the specific configuration of attributes in the present study (Green \& Krieger, 1991; Lee, Moskovitz, \& Lee, 2007). This study was designed using Sawtooth SSI Web 8.4 .6 software, and it consisted of six attributes in a $3 \times 3 \times 2 \times 2 \times 2 \times 2$ design. Table 1 shows the fourteen levels of information (choice sets) used in this study.

Table 1: Attributes and levels (choice sets) used in the conjoint analysis design

\begin{tabular}{|lll|}
\hline Category & Attributes & Levels \\
\hline Visual & Shape of packaging & a) MAP \\
& & b) Vacuum \\
& c) Skin \\
\hline Colour & a) Black \\
& & b) Silver \\
\hline Informational & Freshness & a) Filleted and packed within 6 hours \\
& statements & b) (cognitive) \\
& & c) Shique freshness (affective) \\
& & d) Shelf life - 12 days \\
\hline & Information about & a) Natural mild taste \\
& taste & b) No information \\
\hline Convenience & a) Ready in 15 minutes \\
& b) Quick and easy \\
& c) Skin and boneless \\
\hline
\end{tabular}

In all, nine tasks were shown to the respondents, with each task consisting of three concepts (i.e. alternative products, see picture 1 for example). The consumers were asked to select the most attractive concept for each task (the question is in Norwegian on top of figure 1).

Figure 1: Example of one choice set (text is in Norwegian) 
Hvilket av de følgende produktene er mest attraktivt for deg?

$(1 / 9)$

Produkt 1

\begin{tabular}{|c|c|c|}
\hline & & \\
\hline & & \\
\hline Filetert og pakket innen seks timer & Unik ferskhet & Filetert og pakket innen seks timer \\
\hline Raskt og enkelt & Skinn og beinfri & Ferdig på 15 minutt \\
\hline $\begin{array}{l}12 \text { dager fra slaktedato til siste } \\
\text { forbruksdato }\end{array}$ & $\begin{array}{l}8 \text { dager fra slaktedato til siste } \\
\text { forbruksdato }\end{array}$ & $\begin{array}{l}12 \text { dager fra slaktedato til siste } \\
\text { forbruksdato }\end{array}$ \\
\hline & Naturell mild smak & \\
\hline 0 & 0 & $\bigcirc$ \\
\hline
\end{tabular}

The composition of the tasks and concepts shown per respondent was determined by using a (i) full profile (ii) fractional factorial design: (i) in each concept, respondents were shown levels of every attribute tested, (ii) respondents were only shown a subset of the total number of possible combinations of levels and concepts (i.e. choice situations). Choice situations were chosen per respondent by using the random task generation method and implementing complete enumeration in the Sawtooth SSI Web 8.4.6 software.

In the second step, hierarchical cluster analysis of the part-worth utilities for each attribute level was utilised to identify the specific clusters or segments. In the third step, analysis of variance (ANOVA) was conducted to profile the different consumer clusters. SPSS 23.0 software was used for clustering and conducting the ANOVA.

\section{Results}

\subsection{Conjoint analysis}

Attribute-level part worth and the relative importance of each attribute were estimated for each consumer. Table 2 shows that the cognitive freshness attribute of shelf life was the most important attribute (relative importance of $35.4 \%$ ) for the consumers, followed by convenience $(25.6 \%)$, colour $(16.9 \%)$, freshness statements $(9.0 \%)$, shape of packaging $(7.9 \%)$ and taste $(5.0 \%)$. 
Moreover, the informational attributes were more important (total relative importance $75.1 \%$ ) than the visual attributes (24.9\%).

The consumers found that short shelf life was more important than longer shelf life and that the fish being 'Skin and boneless' was more important than 'Ready in 15 minutes' and 'Quick and easy'. In addition, black packaging was the preferred colour among the consumers. Regarding the freshness statements, the cognitive information of 'Filleted and packed within 6 hours' was more important than the affective statement of 'Unique freshness'. Finally, skin packaging and the taste attribute of 'Natural mild taste' was preferred overall.

Table 2: Mean part-worth utilities and mean relative importance of the attributes

\begin{tabular}{|c|c|c|c|}
\hline Attributes & Levels & $\begin{array}{c}\text { Mean part-worth } \\
\text { utility }\end{array}$ & $\begin{array}{c}\text { Mean relative } \\
\text { importance (\%) }\end{array}$ \\
\hline \multirow[t]{2}{*}{ Shelf life } & 8 days & $0.76(1.01)$ & 35.4 \\
\hline & 12 days & $-0.76(1.01)$ & \\
\hline \multirow[t]{3}{*}{ Convenience } & Ready in 15 minutes & $-0.33(0.70)$ & 25.6 \\
\hline & Quick and easy & $-0.38(0.62)$ & \\
\hline & Skin and boneless & $0.71(1.23)$ & \\
\hline \multirow[t]{2}{*}{ Colour } & Black & $0.36(0.58)$ & 16.9 \\
\hline & Silver & $-0.36(0.58)$ & \\
\hline \multirow[t]{2}{*}{ Freshness statements } & $\begin{array}{l}\text { Filleted and packed } \\
\text { within } 6 \text { hours }\end{array}$ & $0.19(0.41)$ & 9.0 \\
\hline & Unique freshness & $-0.19(0.41)$ & \\
\hline \multirow[t]{3}{*}{ Shape of packaging } & MAP & $-0,16(0,67)$ & 7.9 \\
\hline & Vacuum & $-0.00(0.67)$ & \\
\hline & Skin & $0.17(0.49)$ & \\
\hline \multirow{2}{*}{$\begin{array}{l}\text { Information about } \\
\text { taste }\end{array}$} & Natural mild taste & $0.10(0.28)$ & 5.0 \\
\hline & No information & $-0.10(0.28)$ & \\
\hline
\end{tabular}

\subsection{Cluster analysis}

Hierarchal cluster analysis, performed on the different packaging attributes presented above, provided three clusters with different patterns (Table 3).

Table 3: Mean part-worth utilities and importance of the attributes for the three clusters 


\begin{tabular}{|c|c|c|c|c|c|}
\hline \multirow[t]{2}{*}{ Attributes } & \multirow[t]{2}{*}{ Levels } & \multicolumn{3}{|c|}{ Consumer Segments } & \multirow{2}{*}{$\begin{array}{l}\text { ANOVA } \\
\text { P-value }\end{array}$} \\
\hline & & Quality & Packaging & Convenience & \\
\hline \multirow{3}{*}{ Shelf life } & 8 days & 2.12 & 0.20 & 0.36 & 0.000 \\
\hline & 12 days & -2.12 & -0.20 & -0.36 & 0.000 \\
\hline & Relative importance & $67.5 \%$ & $13.8 \%$ & $10.9 \%$ & \\
\hline \multirow{4}{*}{ Convenience } & Ready in 15 minutes & -0.24 & -0.05 & -1.53 & 0.000 \\
\hline & Quick and easy & -0.26 & -0.15 & -1.45 & 0.000 \\
\hline & Skin and boneless & 0.51 & 0.2 & 2.98 & 0.000 \\
\hline & Relative importance & $12.3 \%$ & $12.1 \%$ & $68.4 \%$ & \\
\hline \multirow[t]{3}{*}{ Colour } & Black & 0.14 & 0.53 & 0.23 & 0.000 \\
\hline & Silver & -0.14 & -0.53 & -0.23 & 0.000 \\
\hline & Relative importance & $4.5 \%$ & $36.7 \%$ & $7.0 \%$ & \\
\hline \multirow[t]{3}{*}{$\begin{array}{l}\text { Freshness } \\
\text { statements }\end{array}$} & $\begin{array}{l}\text { Filleted and packed } \\
\text { within } 6 \text { hours }\end{array}$ & 0.33 & 0.21 & -0.10 & 0.000 \\
\hline & Unique freshness & -0.33 & -0.21 & 0.10 & 0.000 \\
\hline & Relative importance & $10.5 \%$ & $14.5 \%$ & $3.0 \%$ & \\
\hline \multirow{4}{*}{$\begin{array}{l}\text { Shape of } \\
\text { packaging }\end{array}$} & MAP & -0.08 & -0.18 & -0.28 & 0.099 \\
\hline & Vacuum & 0.01 & -0.08 & 0.22 & 0.002 \\
\hline & Skin & 0.07 & 0.26 & 0.07 & 0.000 \\
\hline & Relative importance & $2.4 \%$ & $15.2 \%$ & $7.6 \%$ & \\
\hline Information & Natural mild taste & 0.09 & 0.11 & 0.10 & 0.769 \\
\hline \multirow{2}{*}{ about taste } & no information & -0.09 & -0.11 & -0.10 & 0.769 \\
\hline & Relative importance & $2.9 \%$ & $7.6 \%$ & $3.0 \%$ & \\
\hline $\mathrm{N}$ (\% of sample) & & $\begin{array}{c}141 \\
(28.0 \%)\end{array}$ & $\begin{array}{c}281 \\
(55.9 \%)\end{array}$ & $\begin{array}{c}81 \\
(16.1 \%)\end{array}$ & \\
\hline
\end{tabular}

The segments were named according to the attributes with the highest importance for each cluster (Table 3$)$. The quality segment $(n=141)$ showed a very strong preference for the fish with the shortest shelf life (relative importance of $67.5 \%$ ). Freshness statements were also an important attribute (10.5\%) for this segment, especially with regard to 'Filleted and packed within 6 hours'. In contrast, visual attributes and taste were of very little value for this particular segment. The packaging segment, which was the largest segment $(n=281)$, preferred the two visual attributes of colour and shape (total relative importance of 51.9\%). In addition, black- and skin-packaged products were the most important for this segment. The freshness attributes were also important for this segment (total relative importance of 51.9\%), in addition to convenience. The convenience segment, which was the smallest segment $(n=81)$, placed emphasis on the convenience attributes (relative importance of 68.4\%). They found the 'Skin and boneless' products very important, whereas 'Ready in 15 minutes' and 'Quick and easy' were less important. Overall, freshness and taste had very little value for this segment. Finally, except for taste and MAP packaging, the results of the ANOVA confirmed a significance between the cluster differences in the attribute part-worth utilities (Table 2). 


\subsection{Cluster profiling}

The ANOVA, performed on the different measures, revealed the following three cluster profiles (Table 4). The ANOVA also revealed no significant difference between the segments for the willingness to pay for 2-day- or 4-day-old cod fillets, health orientation, income and gender.

Table 4: Cluster profiles with individual characteristics. Different letters within the same row indicate significant differences $(p \leq 0.05)$

\begin{tabular}{|c|c|c|c|c|}
\hline & \multicolumn{3}{|c|}{ Segment } \\
\hline & & Quality & Packaging & Convenience \\
\hline \multirow[t]{2}{*}{ Consumption } & $\begin{array}{l}\text { Consumption of } \\
\text { fresh cod fillet } \\
\text { (times/year eaten) }\end{array}$ & $21.5 a$ & 21.3a & $12.0 \mathrm{~b}$ \\
\hline & $\begin{array}{c}\text { Share of pre- } \\
\text { packed fresh fish }\end{array}$ & $5.1 b$ & $5.9 a b$ & $6.9 a$ \\
\hline Preference & $\begin{array}{l}\text { Preference fresh } \\
\text { cod fillet }\end{array}$ & $5.7 a$ & $5.3 a b$ & $4.9 \mathrm{~b}$ \\
\hline \multirow[t]{2}{*}{ Involvement } & $\begin{array}{c}\text { Health } \\
\text { involvement }\end{array}$ & 5.7 & 5.6 & 5.6 \\
\hline & Fish involvement & $5.4 a$ & $5.1 \mathrm{ab}$ & $4.7 b$ \\
\hline Knowledge & $\begin{array}{c}\text { Knowledge about } \\
\text { quality }\end{array}$ & $4.6 a$ & $4.2 b$ & $3.7 c$ \\
\hline \multirow[t]{3}{*}{$\begin{array}{l}\text { Willingness to } \\
\text { pay }\end{array}$} & $\begin{array}{l}\text { Willingness to pay } \\
12 \text { hours }\end{array}$ & 112.0ab & $102.8 \mathrm{~b}$ & $122.3 a$ \\
\hline & $\begin{array}{l}\text { Willingness to pay } \\
2 \text { days }\end{array}$ & 93.0 & 106.4 & 102.3 \\
\hline & $\begin{array}{l}\text { Willingness to pay } \\
4 \text { days }\end{array}$ & 69.6 & 77.3 & 85.3 \\
\hline \multirow[t]{3}{*}{ Demographics } & Income & 6.6 & 6.1 & 6.3 \\
\hline & Age & $52.8 a$ & $44.9 \mathrm{~b}$ & $40.4 c$ \\
\hline & Gender & 1.4 & 1.5 & 1.5 \\
\hline
\end{tabular}

The quality segment had the highest consumption rate (21.5 times/year) and preference (mean liking 5.7) for cod fillets. They also ate the lowest amount of pre-packed fish (approximately 50\%).

This segment was the most involved with fish in general, the consumers were the oldest (mean age 52.8 years) and they had the most knowledge about the quality of fish.

The packaging segment had (together with the quality segment) the highest consumption rate (21.3 times/year), but it was not significantly different in preference from the other two segments. They also had the lowest willingness to pay for 12-hour-old fish (102.8 Norwegian kroners). In addition, they were between the two other segments in terms of quality knowledge and age.

The convenience segment had the lowest consumption rate (12.0 times/year) and preference (mean liking 4.9) for cod fillets. They also had the least amount of knowledge about the quality of 
fish. Moreover, they had the highest willingness to pay for 12-hour-old fish (122.3 Norwegian kroners), and they ate the most pre-packed fish (approximately 70\%). Finally, this segment, which was the youngest (mean age 40.4 years), was not involved with fish in general.

\section{Discussion}

The first goal of this study was to evaluate the relative importance of the visual and informational packaging attributes of fresh cod. The results show that informational attributes were more important than visual attributes. In a similar study, Silayoi and Speece (2007) found that visual and informational attributes had the same importance. However, they included more visual attributes than informational ones in their study. In contrast, this study included more informational attributes than visual ones, which may be one explanation for the results. The most important factors for consumers when choosing cod fillets were the two freshness attributes (total relative importance of 44.5\%). The findings show that information about shelf life (number of days) was much more important (relative importance of 35.4\%) than statements about freshness (relative importance of 9.0\%). This supports Raegart et al. (2004), who found that shelf life is used as a proxy for credence attributes, such as information about freshness in consumer decision-making process. The consumers in this study found cognitive information about freshness ('Filleted and packed within 6 hours') more important than affective information ('Unique freshness'). This indicates that these consumers had a low need for affect and a high need for cognition regarding information about freshness (Haddock et al., 2008). This is also supported by the high importance of shelf life, which was one of the cognitive freshness information items in the present study.

The second-most important packaging attribute was convenience (relative importance of 25.6\%). The consumers were more attracted to a product that was 'Skin and boneless' rather than 'Quick and easy' to prepare. Previous studies have shown that bones are one of the main concerns associated with fish consumption (Olsen, 2003; Verbeke \& Vackier, 2005). Other studies (Bruns $\varnothing$ et al., 2009) show that in some countries (e.g. Belgium), time used in preparation is the biggest barrier for fish consumption, whereas bones are more important in other countries (e.g. Spain). Thus, the fact that boneless cod fillets were perceived as more important than time used in preparation might be a result of the country in which the study was conducted.

Information about taste came out as the least important attribute. This is somewhat surprising given that previous studies found taste as one of the most important informational attributes (Tepper, \& Trail, 1998; Cardello, \& Schutz, 2003). A possible explanation is that the consumers already know the taste of cod, and that we did not introduce any new flavors (i.e added spices or brine) of cod in our study. 
The second goal of this study was to segment the consumers based on preference for different packaging attributes and validate the segments using individual characteristics of the consumers. Using the visual and informational attributes for market segmentation purposes through cluster analysis revealed three segments; the packaging, quality and convenience segment. Although informational attributes were found to be the most important in this study in general, the packaging segment, which was the largest (more than $50 \%$ of the consumers), preferred the visual attributes of shape and colour. Freshness attributes were also important (total relative importance $28.4 \%$ ). In this segment short shelf life and the cognitive freshness statement were of similar importance. This was a different result compared with the entire sample, which preferred short shelf life to freshness statements.

The quality segment and the convenience segment were mainly concerned about informational attributes. More specifically, the quality segment preferred cognitive quality indicators such as short shelf life and cognitive freshness statements. Meanwhile, the convenience segment used convenience information and preferred fish that was skin and boneless.

As mentioned in the introduction section, pre-packed fillets of salmon have been available in the Norwegian market for some time. Familiarity with a product can influence which information cues consumers rely on when evaluating a product (Rao \& Monroe, 1988). Thus, different levels of familiarity with pre-packed salmon could explain why the different segments emphasised different attributes.

The individual characteristics of the segments also differed. For example, the quality segment was highly involved in fish, had high subjective knowledge and the consumers had a high consumption and preference for cod. This is in accordance with previous research, which showed that highly involved consumers with high subjective knowledge tend to consume fish more frequently (Olsen, 2001; Verbeke et al., 2007). This was also the segment with the oldest consumers; thus, they had the most experience dealing with fish. This was also reflected in the fact that they had the most knowledge of how to judge quality, which is in line with previous research (Verbeke et al., 2007). In addition, the quality segment bought both packaged and unpackaged fish.

The packaging segment had high consumption rate and preference for cod, and they were highly involved in fish. However, this segment had the lowest willingness to pay for extremely fresh fish, showing that they focused more on the packaging than on quality attributes. They were also between the two other segments in terms of age and knowledge of how to judge the quality of fish. This shows that lower subjective knowledge does not necessarily result in lower consumption, something that has been shown in other studies (Altintzoglou, \& Heide, 2016). 
The convenience segment had the lowest frequency of cod consumption and the lowest

preference for cod. This segment had the youngest consumers, and they expressed lower involvement in fish compared with the two other segments. Previous research has shown that younger consumers are generally less involved in fish, and they perceive the inconvenient aspects of fish as a barrier to consumption (Olsen, 2003). In this study, they had limited knowledge of how to evaluate the quality of fish and the highest willingness to pay for extremely fresh fish. This may be explained by their limited knowledge about quality evaluation. More specifically, as these consumers were probably insecure about the quality of fish, they were willing to pay more for fresh fish to reduce their risk of purchasing low-quality fish. Finally, this segment also purchased the most prepacked fish, which can be explained by the fact that pre-packed fish in Norway is mostly sold skinless and boneless, both of which fit the segment profile.

This study did not show significant difference in health involvement between the segments. Previous studies has shown a positive relationship between health involvement and consumption (Olsen, 2003). The study did however show a significant relationship between fish involvement and consumption, indication that this could be a better predictor for consumption, at least in the context of this study.

\subsection{Implications}

The results of this study can be used by the seafood industry to design packaging for cod products that better matches Norwegian consumers' needs and expectations. In general, freshness seems to be the most important product attribute for consumers. Offering products of high quality and freshness appears to be a good strategy for building a good image and increasing the sales of cod.

This study identified three distinct clusters that can be targeted by the seafood industry, with emphasis on different packaging attributes:

1. The packaging segment, the largest segment, had a high consumption rate of fresh cod fillets. Thus, it seems to be the most promising segment to focus on for the seafood industry. Visual packaging attributes were the most important for this segment. Accordingly, designing attractive packaging could be a good strategy for targeting this particular segment. In addition, these consumers were somewhat interested in the freshness indicators, and they found the freshness attributes equally important. In this regard, both short shelf life and cognitive freshness statements should be used on packaging. Finally, this segment had the lowest willingness to pay for extremely fresh cod, and the consumers were willing to pay the 
same amount regardless of whether the fish was packaged 12 hours or two days earlier. Overall, compared with the other segments, this segment accepted less freshness for the same price.

2. The convenience segment was less involved in fish, had less knowledge about quality and consumed less cod fillets than the other segments. At the same time, they had a high willingness to pay for extremely fresh cod, and they were very attracted to skin and boneless fillets. Thus, these consumers should be targeted with products that are more convenient, skin and, boneless and extremely fresh. It would also be interesting to gain more knowledge about their general drivers for food consumption to tailor new cod products that are better suited to their specific needs and preferences. Over time, this can help increase their consumption of fresh cod.

3. The quality segment had the most knowledge, involvement with and consumption of fresh cod fillets. Their main emphasis was on freshness indicators, especially short shelf life and, to a lesser degree, cognitive freshness statements. They also had a high willingness to pay for extremely fresh products. Therefore, this segment can be targeted with extremely fresh cod products in which freshness is emphasised by both short shelf life and cognitive statements.

\subsection{Limitations and future research}

The results of this study should be interpreted in the cultural context in which it was conducted. Malai and Speece (2005) argued that there could be several levels of cultural impact at work in conditioning any response to marketing elements. As an example, people in different cultures are exposed to different colours; thus, they develop colour preferences based on their own cultures (Silayoi, \& Speece, 2007). Previous research has also shown that perception of cues for a food product can have both similarities and differences between countries (Grunert, 1997). Future research on packaging attributes for fresh fish should be performed in a cross-cultural context to validate and generalise the findings. Another limitation of this study is that the consumers could not evaluate real products with different packaging attributes. Measurement refinements may also be made in future research. For example do we find several ways to assess involvement (Mittal, 1995; Zaichkowsky, 1985).

Research has shown that evaluation of a product can change from when a consumer assesses a product concept to when evaluating a real product (Grunert et al., 2011; Saeed, Grunert, \& Therkildsen, 2013). Therefore, future research should be conducted in more-realistic environments, with real products. Finally, several construct reliability issues can be discussed. For example was WTP 
assessed with a direct measure without any commitment to pay. Future studies could use other forms of assessment such as an incentive-aligned choice-based conjoint analysis (Ding, 2007) or in real WTP situations (Voelckner, 2006).

\section{Conclusions}

In this study, informational attributes (freshness statements, information about taste and convenience) were found to be more important than visual attributes (shape of packaging and colour), especially for consumer evaluations and their choices of fresh cod in Norway. The most important factors for consumers when choosing cod fillets were the two freshness attributes. In addition, the consumers found cognitive freshness (shelf life and 'Filleted and packed within 6 hours') information more important than affective or emotional information ('Unique freshness'). The results of the cluster analysis revealed three distinct segments (packaging, convenience and quality) that emphasised different packaging attributes. Furthermore, the segments were significantly different in terms of the individual characteristics, consumption, preference, involvement, knowledge, willingness to pay and demographics. This result underlines the importance of segmenting consumers to be more efficient and effective when meeting the specific needs of the target audience (Verbeke, 2008).

\section{Acknowledgements}

The authors thank the Research Council of Norway for financial support (grant 233751/E50).

\section{References}

Aikman, S. N., Crites, S. L., \& Fabrigar, L. R. (2006). Beyond Affect and Cognition: Identification of the Informational Bases of Food Attitudes. Journal of Applied Social Psychology, 36(2), 340-382.

Alfnes, F., Guttormsen, A. G., Steine, G., \& Kolstad, K. (2006). Consumers' willingness to pay for the color of salmon: a choice experiment with real economic incentives. American Journal of Agricultural Economics, 88(4), 1050-1061. 
Altintzoglou, T., \& Heide, M. (2016). Fish quality and consumers: how do consumers' knowledge about and involvement in fish quality define factors that influence fish buying behavior. Journal of Aquatic Food Product Technology, 25(6), 885-894.

Ampuero, O., \& Vila, N. (2006). Consumer perceptions of product packaging. Journal of Consumer Marketing, 23(2), 100-112.

Ares, G., \& Deliza, R. (2010). Identifying important package features of milk desserts using free listing and word association. Food Quality and Preference, 21(6), 621-628.

Azzi, A., Battini, D., Persona, A., \& Sgarbossa, F. (2012). Packaging design: General framework and research agenda. Packaging Technology and Science, 25(8), 435-456.

Becker, L., van Rompay, T. J., Schifferstein, H. N., \& Galetzka, M. (2011). Tough package, strong taste: The influence of packaging design on taste impressions and product evaluations. Food Quality and Preference, 22(1), 17-23.

Berry, L. L., Seiders, K., \& Grewal, D. (2002). Understanding service convenience. Journal of Marketing, 66(3), 1-17.

Boninger, D. S., Krosnick, J. A., \& Berent, M. K. (1995). Origins of attitude importance: self-interest, social identification, and value relevance. Journal of Personality and Social Psychology, 68(1), 61.

Breidert, C., Hahsler, M., \& Reutterer, T. (2006). A review of methods for measuring willingness-topay. Innovative Marketing, 2(4), 8-32.

Bruns $\varnothing$, K., Fjord, T. A., \& Grunert, K. G. (2002). Consumers food choice and quality perception. MAPP working paper no 77. Aarhus: The Aarhus School of Business, MAPP Centre.

Bruns $\varnothing$, K., Verbeke, W., Olsen, S. O., \& Jeppesen, L. F. (2009). Motives, barriers and quality evaluation in fish consumption situations: Exploring and comparing heavy and light users in Spain and Belgium. British Food Journal, 111(7), 699-716.

Candel, M. J. (2001). Consumers' convenience orientation towards meal preparation: conceptualization and measurement. Appetite, 36(1), 15-28. 
627 Cardello, A. V., \& Schutz, H. G. (2003). The importance of taste and other product factors to 628 consumer interest in nutraceutical products: Civilian and military comparisons. Journal of Food Science, 68(4), 1519-1524.

630

Carlucci, D., Nocella, G., De Devitiis, B., Viscecchia, R., Bimbo, F., \& Nardone, G. (2015). Consumer purchasing behaviour towards fish and seafood products. Patterns and insights from a sample of international studies. Appetite, 84, 212-227.

Deliza, R., \& MacFie, H. J. (1996). The generation of sensory expectation by external cues and its effect on sensory perception and hedonic ratings: a review. Journal of Sensory Studies, 11(2), 103-

DeSarbo, W. S., \& DeSarbo C. F. (2013). A generalized normative segmentation methodology employing conjoint analysis. IN A. Gustafsson, A., Herrmann, A., \& Huber, F. (Eds.). (2013). Conjoint measurement: Methods and applications (pp.321-347). Berlin Heidelberg: Springer Science \& Business Media.

Ding, M. (2007). An incentive-aligned mechanism for conjoint analysis. Journal of Marketing Research, 44(2), 214-223.

Gil, J. M., \& Sánchez, M. (1997). Consumer preferences for wine attributes: a conjoint approach. 
Gofton, L. (1995). Convenience and the moral status of consumer practices. In D.W. Marshall (Ed.), Food choice and the consumer (pp. 152-181). London: Blackie Academic \& Professional.

Golan E., Kuchler F., Mitchell L., Greene C., \& Jessup A. (2001). Economics of food labelling. Journal of Consumer Policy, 24, 117-184

Grebitus, C., Jensen, H. H., Roosen, J., \& Sebranek, J. G. (2013). Fresh meat packaging: Consumer acceptance of modified atmosphere packaging including carbon monoxide. Journal of Food Protection, 76(1), 99-107.

Green, P. E., \& Krieger, A. M. (1991). Product design strategies for target-market positioning. Journal of Product Innovation Management, 8, 189-202.

Green, P. E., Krieger, A. M., \& Wind, Y. (2001). Thirty years of conjoint analysis: Reflections and prospects. Interfaces, 31(3 supplement), 56-73.

Grimes, A., \& Doole, I. (1998). Exploring the relationships between colour and international branding: A cross cultural comparison of the UK and Taiwan. Journal of Marketing Management, 14(7), 799817.

Grunert, K. G. (1997). What's in a steak? A cross-cultural study on the quality perception of beef. Food Quality and Preference, 8(3), 157-174.

Grunert, K. G., Verbeke, W., Kügler, J. O., Saeed, F., \& Scholderer, J. (2011). Use of consumer insight in the new product development process in the meat sector. Meat Science, 89(3), 251-258.

Huskinson, T. L., \& Haddock, G. (2004). Individual differences in attitude structure: Variance in the chronic reliance on affective and cognitive information. Journal of Experimental Social Psychology, 40(1), 82-90.

Haddock, G., Maio, G. R., Arnold, K., \& Huskinson, T. (2008). Should persuasion be affective or cognitive? The moderating effects of need for affect and need for cognition. Personality and Social Psychology Bulletin, 34(6), 769-778. 
Hair, J. F., Anderson, R. E., Tatham, R. L., \& William, C. (1998). Multivariate data analysis (5 $5^{\text {th }}$ ed.). New Jersey: Prentice Hall International.

Harcar, T., \& Karakaya, F. (2005). A cross-cultural exploration of attitudes toward product expiration dates. Psychology \& Marketing, 22(4), 353-371.

Juhl, H. J., \& Poulsen, C. S. (2000). Antecedents and effects of consumer involvement in fish as a product group. Appetite, 34, 261-267.

Karimi, P., Mahdieh, O., \& Rahmani, M. (2013). The study of relationship between packaging elements and purchase behavior: consumers of food, cosmetics and health products. Interdisciplinary Journal of Contemporary Research in Business, 5, 281-295.

Knetsch, J. L., \& Sinden, J. A. (1984). Willingness to pay and compensation demanded: Experimental evidence of an unexpected disparity in measures of value. The Quarterly Journal of Economics, 507521.

Koutsimanis, G., Getter, K., Behe, B., Harte, J., \& Almenar, E. (2012). Influences of packaging attributes on consumer purchase decisions for fresh produce. Appetite, 59(2), 270-280.

Labrecque, L. I., \& Milne, G. R. (2012). Exciting red and competent blue: the importance of color in marketing. Journal of the Academy of Marketing Science, 40(5), 711-727.

Labrecque, L. I., Patrick, V. M., \& Milne, G. R. (2013). The marketers' prismatic palette: A review of color research and future directions. Psychology \& Marketing, 30(2), 187-202.

Lee, C. M., Moskovitz, H. R., \& Lee, S. -Y. (2007). Expectations, needs and segmentation of healthy breakfast cereal consumers. Journal of Sensory Studies, 22, 587-607.

Malai, V., \& Speece, M. (2005). Cultural impact on the relationship among perceived service quality, brand name value, and customer loyalty. Journal of International Consumer Marketing, 17(4), 7-39.

Marshall, D., \& Bell, R. (2004). Relating the food involvement scale to demographic variables, food choice and other constructs. Food Quality and Preference, 15(7), 871-879. 
Marshall, D., Stuart, M., \& Bell, R. (2006). Examining the relationship between product package colour and product selection in preschoolers. Food Quality and Preference, 17, 615-621.

Miller, K. M., Hofstetter, R., Krohmer, H., \& Zhang, Z. J. (2011). How should consumers' willingness to pay be measured? An empirical comparison of state-of-the-art approaches. Journal of Marketing Research, 48(1), 172-184.

Mittal, B. (1995). A comparative analysis of four scales of consumer involvement. Psychology \& Marketing, 12(7), 663-682.

Mueller Loose, S. M., Peschel, A., \& Grebitus, C. (2013). Quantifying effects of convenience and product packaging on consumer preferences and market share of seafood products: The case of oysters. Food Quality and Preference, 28(2), 492-504.

Nancarrow, C., Wright, T. L., Brace, I. (1998) Gaining competitive advantage from packaging and labelling in marketing communications. British Food Journal, 100(2), 110-118.

Olsen, S. O. (2001). Consumer involvement in seafood as family meals in Norway: an application of the expectancy-value approach. Appetite, 36(2), 173-186.

Olsen, S. O. (2003). Understanding the relationship between age and seafood consumption: the mediating role of attitude, health involvement and convenience. Food Quality and Preference, 14(3), 199-209.

Olsen, S. O. (2004). Antecedents of seafood consumption behaviour: An overview. Journal of Aquatic Food Product Technology, 13(3), 79-91

Olsen, S. O., \& Ruiz, S. (2008). Adolescents' influence in family meal decisions. Appetite, 51(3), 646653.

Olsen, S. O., Scholderer, J., Brunso, K., \& Verbeke, W. (2007). Exploring the relationship between convenience and fish consumption: a cross-cultural study. Appetite, 9, 84-91. 
Otterå, H., Carlehög, M., Karlsen, Ø., Akse, L., Borthen, J., \& Eilertsen, G. (2007). Effect of diet and season on quality of farmed Atlantic cod (Gadus morhua L.). LWT-Food Science and Technology, 40(9), 1623-1629.

Petty, R. E., Briñol, P., Loersch, C., \& McCaslin, M. J. (2009). The need for cognition. Handbook of Individual Differences in Social Behavior, 318-329.

Pieniak, Z., Verbeke, W., Olsen, S. O., Hansen, K. B., \& Bruns $\emptyset$, K. (2010). Health-related attitudes as a basis for segmenting European fish consumers. Food Policy, 35(5), 448-455.

Pieniak, Z., Verbeke, W., \& Scholderer, J. (2010). Health-related beliefs and consumer knowledge as determinants of fish consumption. Journal of Human Nutrition and Dietetics, 23(5), 480-488.

Pieniak, Z., Verbeke, W., Scholderer, J., Brunsø, K., \& Ottar Olsen, S. (2008). Impact of consumers' health beliefs, health involvement and risk perception on fish consumption: A study in five European countries. British Food Journal, 110(9), 898-915.

Pieniak, Z., Verbeke, W., Scholderer, J., Bruns $\varnothing$, K., \& Olsen, S. O. (2007). European consumers' use of and trust in information sources about fish. Food Quality and Preference, 18(8), 1050-1063.

Ragaert, P., Verbeke, W., Devlieghere, F., \& Debevere, J. (2004). Consumer perception and choice of minimally processed vegetables and packaged fruits. Food Quality and Preference, 15(3), 259-270.

Raghubir, P., \& Greenleaf, E. A. (2006). Ratios in proportion: what should the shape of the package be?. Journal of Marketing, 70(2), 95-107.

Rao, A. R., \& Monroe, K. B. (1988). The moderating effect of prior knowledge on cue utilization in product evaluations. Journal of Consumer Research, 15(2), 253-264.

Saeed, F., Grunert, K. G., \& Therkildsen, M. (2013). How product trial changes quality perception of four new processed beef products. Meat Science, 93(1), 119-127.

Sapp, S. G., \& Jensen, H. H. (1998). An evaluation of the health belief model for predicting perceived and actual dietary quality1. Journal of Applied Social Psychology, 28(3), 235-248. 
Sattler, H., \& Hensel-Börner, S. (2003). A comparison of conjoint measurement with self-explicated approaches. In A. Gustafsson, A. Herrmann \& F. Huber (Eds.), Conjoint measurement (pp. 147-159). Berlin Heidelberg: Springer.

Schifferstein, H. N., Fenko, A., Desmet, P. M., Labbe, D., \& Martin, N. (2013). Influence of package design on the dynamics of multisensory and emotional food experience. Food Quality and Preference, 27(1), 18-25.

Shepherd, R., \& Raats, M. M. (1996). Attitudes and beliefs in food habits. In H. L. Meiselman \& H. J. H. MacFie (Eds.), Food choice, acceptance and consumption (pp. 346-364). US: Springer.

Silayoi, P., \& Speece, M. (2004). Packaging and purchase decisions: An exploratory study on the impact of involvement level and time pressure. British Food Journal, 106(8), 607-628.

Silayoi, P. \& Speece, M. (2007). The importance of packaging attributes a conjoint analysis approach. European Journal of Marketing, 41, 1.495-1.517.

Singh, S. (2006). Impact of color on marketing. Management Decision, 44(6), 783-789.

Steptoe, A., Pollard, T. M., \& Wardle, J. (1995). Development of a measure of the motives underlying the selection of food: the food choice questionnaire. Appetite, 25(3), 267-284.

Tepper, B. J., \& Trail, A. C. (1998). Taste or health: A study on consumer acceptance of corn chips. Food Quality and Preference, 9(4), 267-272.

Verbeke, W. (2008). Impact of communication on consumers' food choices. Proceedings of the Nutrition Society, 67(03), 281-288.

Verbeke, W., \& Vackier, I. (2005). Individual determinants of fish consumption: application of the theory of planned behaviour. Appetite, 44(1), 67-82.

Verbeke, W., Vermeir, I., \& Brunsø, K. (2007). Consumer evaluation of fish quality as basis for fish market segmentation. Food Quality and Preference, 18(4), 651-661.

Vigneron, F., \& Johnson, L. W. (2004). Measuring perceptions of brand luxury. The Journal of Brand Management, 11(6), 484-506. 
827 Voelckner, F. (2006). An empirical comparison of methods for measuring consumers' willingness to pay. Marketing Letters, 17(2), 137-149.

Wansink, B., \& Wright, A. O. (2006). "Best if used by..." How freshness dating influences food acceptance. Journal of Food Science, 71(4), 354-357.

832

Wertenbroch, K., \& Skiera, B. (2002). Measuring consumers' willingness to pay at the point of purchase. Journal of Marketing Research, 39(2), 228-241.

Zaichkowsky, J. L. (1985). Measuring the involvement construct. Journal of Consumer Research, 341352.

Zeithaml, V. A. (1988). Consumer perceptions of price, quality, and value: a means-end model and synthesis of evidence. The Journal of Marketing, 2-22.

Zhang, Y., Feick, L., \& Price, L. J. (2006). The impact of self-construal on aesthetic preference for angular versus rounded shapes. Personality and Social Psychology Bulletin, 32(6), 794-805.

Zhang, T., Lusk, K., Mirosa, M., \& Oey, I. (2016). Understanding young immigrant Chinese consumers' freshness perceptions of orange juices: A study based on concept evaluation. Food Quality and Preference, 48, 156-165.

$\emptyset$ stli, J., Esaiassen, M., Garitta, L., Nøstvold, B., \& Hough, G. (2013). How fresh is fresh? Perceptions and experience when buying and consuming fresh cod fillets. Food Quality and Preference, 27(1), 2634. 